\title{
norden
}

\section{EPR systems and new business models}

- reuse and recycling of textiles in the Nordic region
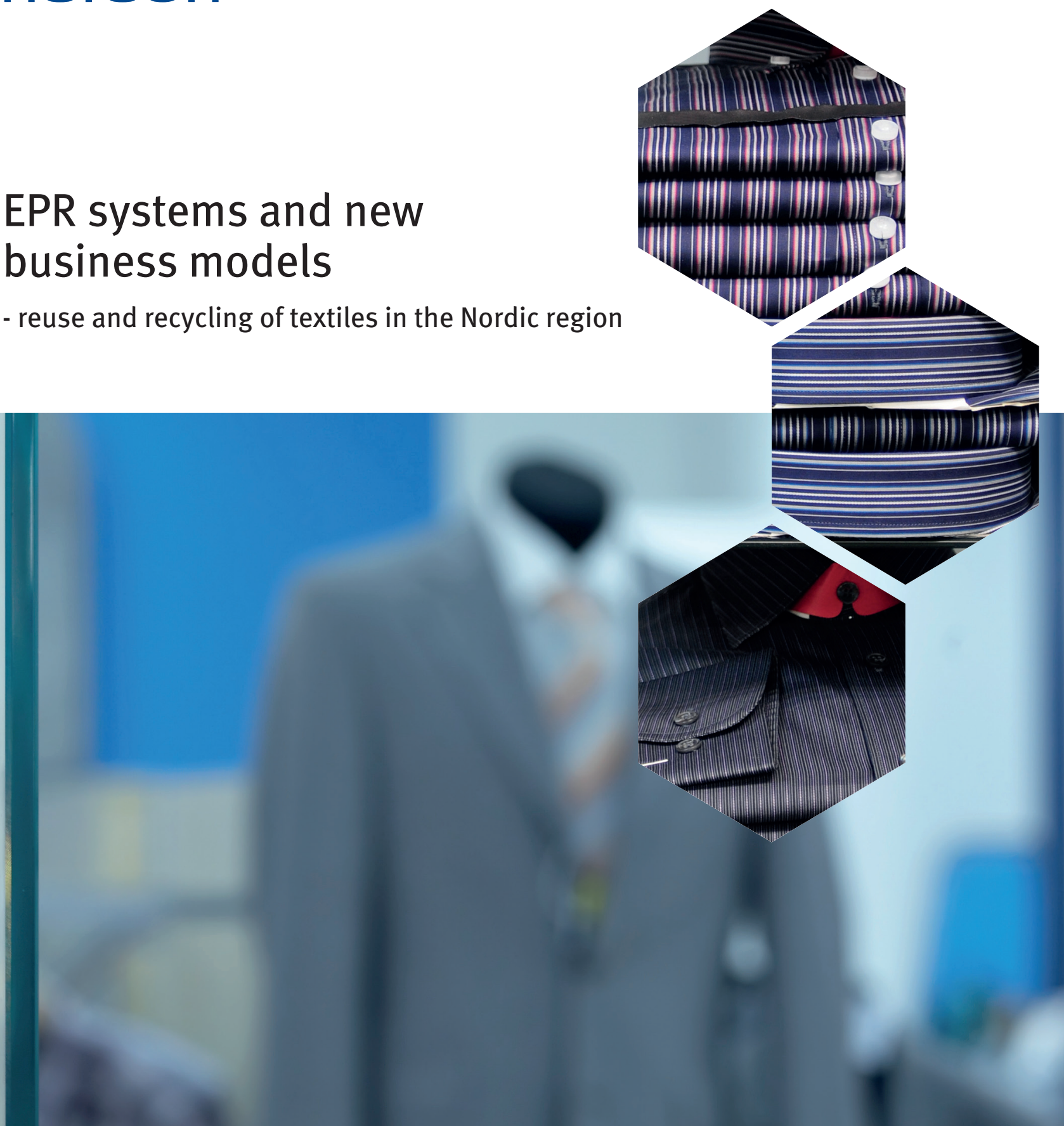

/Policy brief 
EPR systems and new business models

- reuse and recycling of textiles in the Nordic region

ISBN 978-92-893-4023-6 (PRINT)

ISBN 978-92-893-4024-3 (PDF)

http://dx.doi.org/10.6027/ANP2015-721

ANP 2015:721

(C) Nordic Council of Ministers 2015

Layout: Gitte Wejnold

Cover photo: SignElements

Photo: SignElements

Print: Rosendahls-Schultz Grafisk

Copies: 40

Typeface: Meta LF

Paper: Munken Polar

Printed in Denmark

www.norden.org/en/publications

\section{Nordic co-operation}

Nordic co-operation is one of the world's most extensive forms of regional collaboration, involving Denmark, Finland, Iceland, Norway, Sweden, and the Faroe Islands, Greenland, and Åland.

Nordic co-operation has firm traditions in politics, the economy, and culture. It plays an important role in European and international collaboration, and aims at creating a strong Nordic community in a strong Europe.

Nordic co-operation seeks to safeguard Nordic and regional interests and principles in the global community. Common Nordic values help the region solidify its position as one of the world's most innovative and competitive.

\section{Nordic Council of Ministers}

Ved Stranden 18

DK-1061 Copenhagen $\mathrm{K}$

Telefon (+45) 33960200

www.norden.org 


\section{EPR systems and new business models}

- reuse and recycling of textiles in the Nordic region

Policy brief

David Watson, Copenhagen Resource Institute

Nikola Kiørboe, Copenhagen Resource Institute 


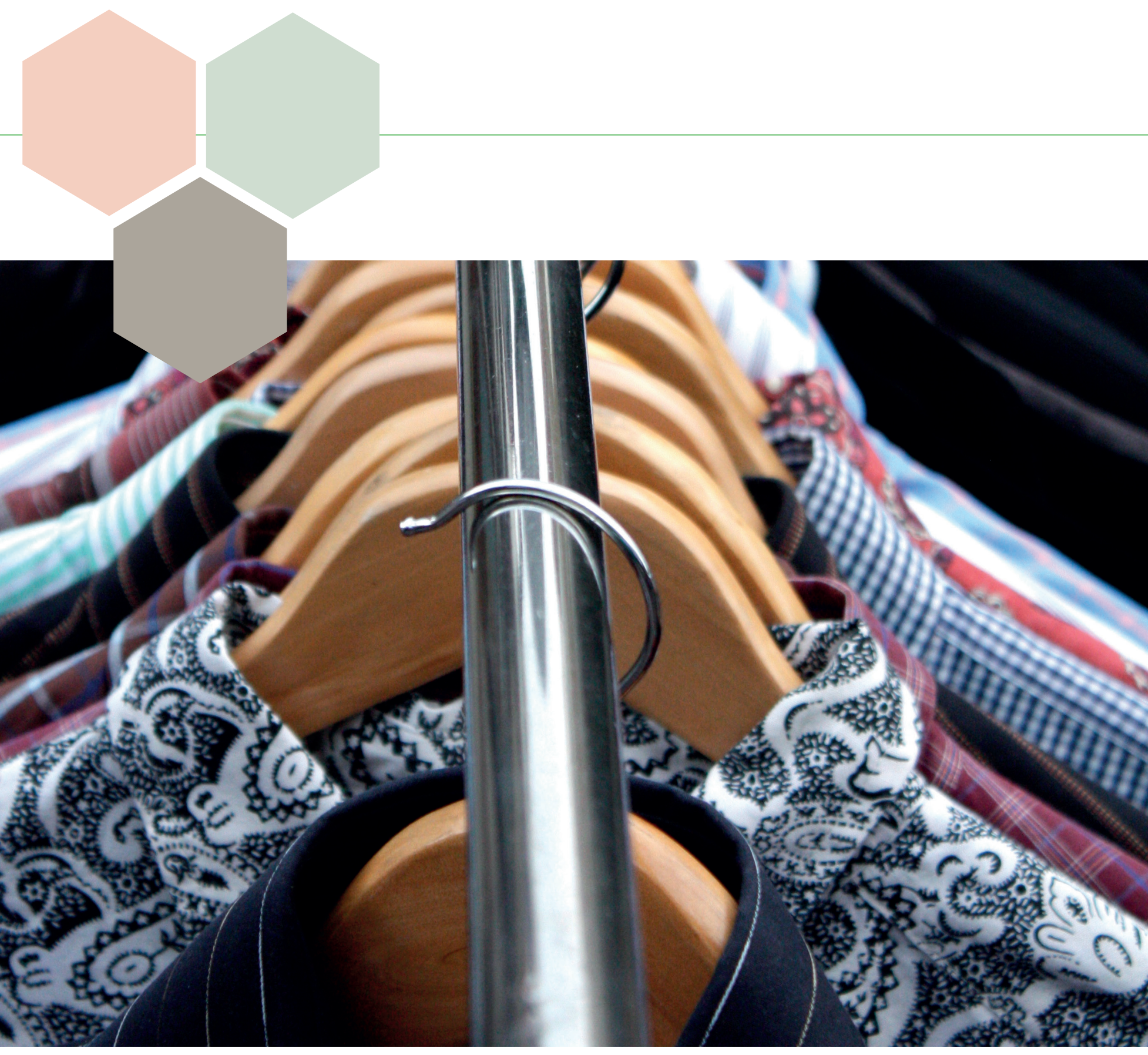




\section{Introduction}

There is a need for well-functioning systems and business models to improve the reuse and recycling of textiles in the Nordic region. Clearer responsibilities in the value chain can provide incentive for improvements, while innovative and more sustainable business models provide an opportunity for improving profitability, consumer satisfaction, and reducing resource use and environmental impact.

This project developed and proposed three policy packages, encouraging the establishment of extended producer responsibility (EPR) systems and innovative new business models. These policy packages provide Nordic authorities and textile businesses with tools for promoting effective new business models and EPR systems.

The suggested systems and businesses models can provide considerable environmental benefits by offsetting the production of new textile products and new fibres, and at the same time promote Nordic competitiveness and job creation.

Well-established collection systems already exist for some types of textiles, particularly clothing, in all the Nordic countries. These are generally operated by charities, but also in some cases by business. It is important that any proposed EPR systems or innovative business models avoid negatively impacting existing collection systems.

New systems should focus on filling the gaps left by current systems and business models, i.e. by increasing the collection, reuse and recycling of textiles other than clothing; by increasing the collection of textiles which are not fit for reuse; or by developing and implementing business models that focus on sharing or leasing of clothes.

Each policy package includes a number of complementary policy instruments. However, elements within each package could also be implemented individually or combined with elements from other packages.

This policy brief is part of the Nordic Prime Ministers' initiative, The Nordic Region - leading in green growth. Read more in the web magazine Green Growth the Nordic Way at www.nordicway.org or at norden.org/greengrowth 


\section{Extended Producer Responsibility}

The term "Extended Producer Responsibility" (EPR) is based on the "polluter pays" principle, in the sense that it makes manufacturers responsible for the entire life cycle of their products. The EPR-scheme is $a$ policy principle to promote total life cycle environmental improvements of product systems by extending the responsibilities of the manufacturer of the product to various parts of the product's life cycle, and especially to the take-back, recovery and final disposal of the product.

Part of the rationale for the EPR approach is that placing responsibility for the end-of-life management of products on the manufacturer and/or importer will lead to improvements along the entire life cycle. More specifically, EPR should provide producers and importers with incentives to manage products more efficiently and with less environmental risk, by taking measures both up-stream and downstream from sale.

Up-stream measures include designing products to be more suitable for reuse, including increasing product quality, reducing the use of toxic and hazardous substances, and designing for disassembly and recycling. Downstream measures include the design of systems to increase collection rates, enhance reuse and recycling, and more environmentally sound treatment of end-of-use products.
EPR systems involve a range of actors. These are primarily the administrative authority (responsible for ensuring that the EPR legislation is implemented and adhered to), the Producer Responsibility Organization (the PRO negotiates contracts with operators), producers, operators (e.g. municipalities, charities and businesses that collect post-consumer or unsold textiles), sorters, municipalities (may be responsible for distributing information to households), and private households.

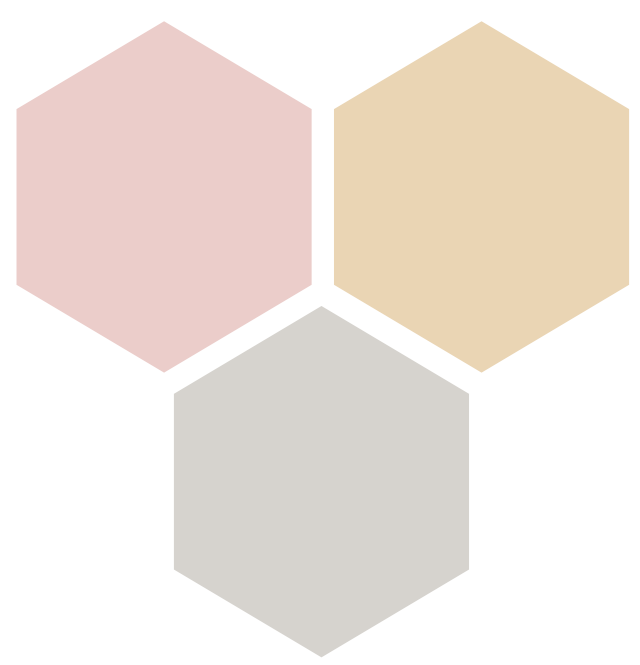




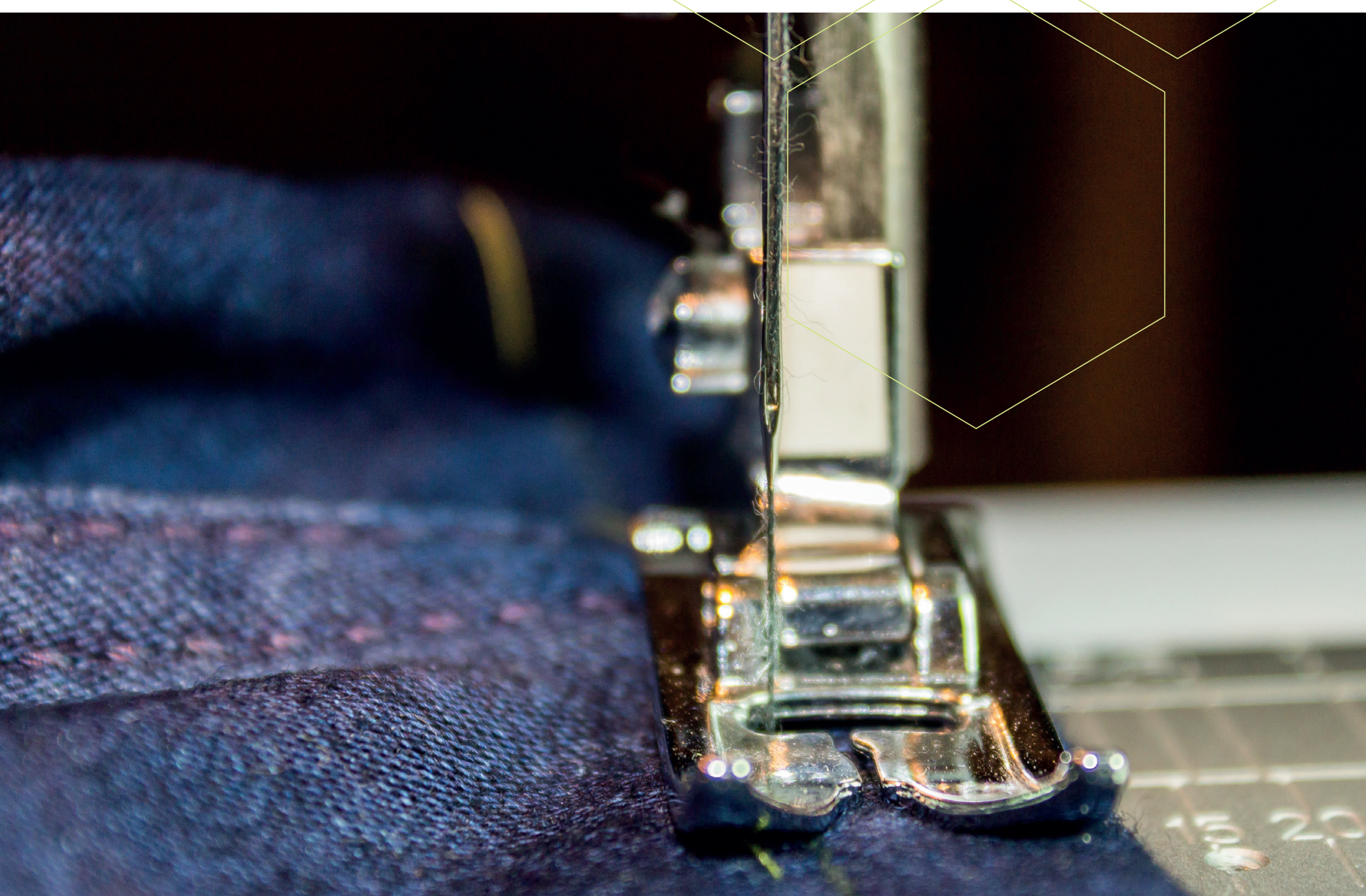




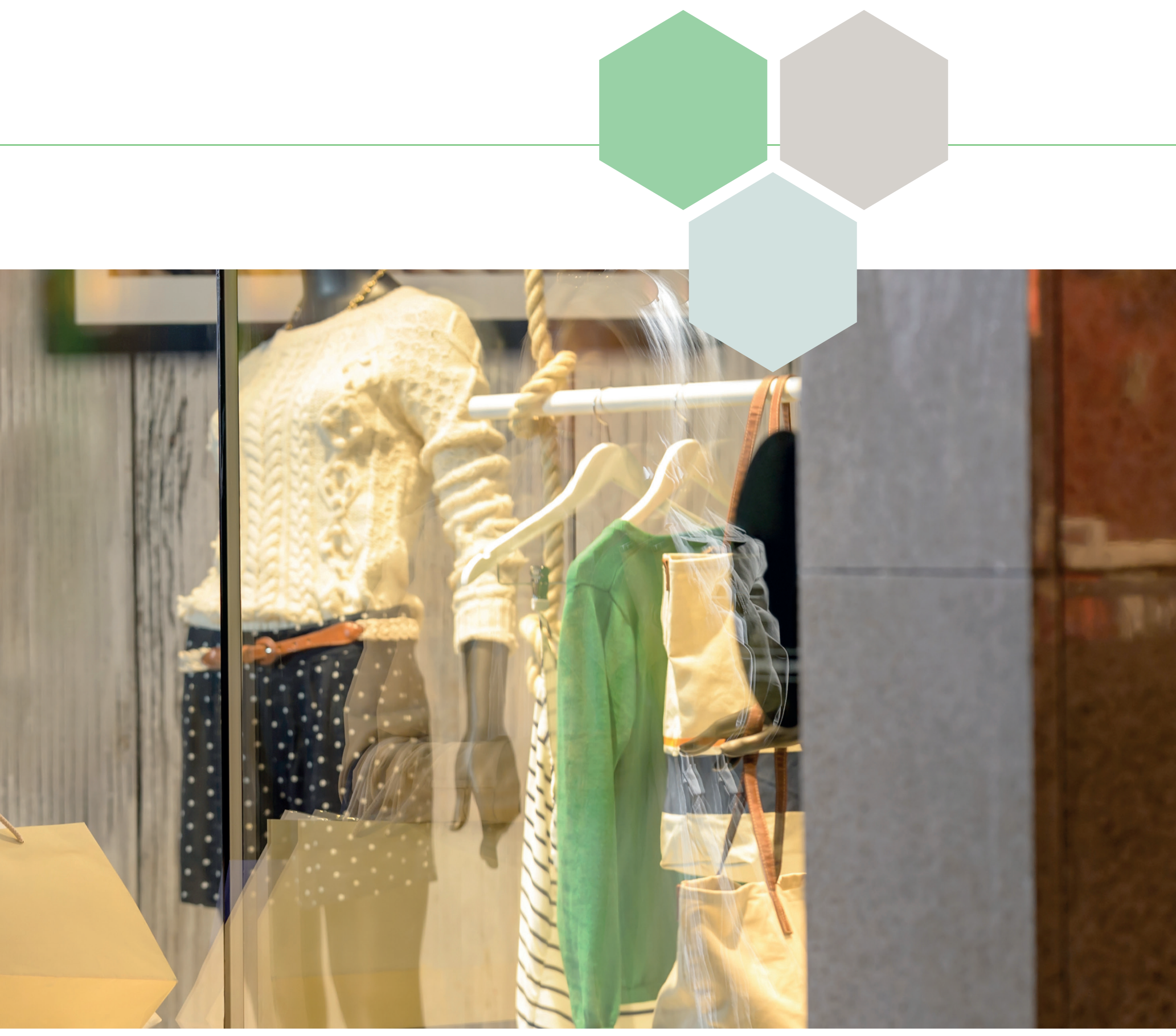




\section{Policy package 1 - key findings}

\section{Mandatory extended producer responsibility (EPR) complemented by a tax on hazardous chemicals in textiles}

The key goal of this policy package is to establish a mandatory EPR system to increase the share of sold new textiles that are - following end of use by the original owner - separately collected and made available for reuse, and, where reuse is no longer possible, for recycling.

While there is a healthy Nordic and export market for reusable clothing, the recycling market for textiles that are no longer suitable for reuse is weak due to current technical difficulties in separating and sorting fibres. EPR can potentially aid this situation by encouraging a modified design of textile products, making them more suitable for reuse and subsequently for closed loop recycling.
Critical factors of the mandatory

EPR policy package and its implementation include:

- Setting ambitious but realistic targets for collection, reuse and recycling

- Clearly defining what textiles are included and who can claim ownership of reusable textiles

- Informing households that all textile products, both reusable and non-reusable, are accepted by the system

- Enhancing the convenience for citizens in both urban and rural areas, coupled with ample information

- Negotiating between competing interests when constructing the PRO and deciding how many PRO's should be allowed

- Creating a fee structure for producers that rewards those who make positive upstream changes to product design
- Avoiding creating barriers for entering the market

- The possibility to embrace new business models

New EPR systems should avoid undermining existing charity organisation collection by encouraging charities to be operators (both collectors and sorters) under a mandatory EPR system. Costs incurred by charity organisations from increased administration, sorting and handling of increased volumes of recyclable textiles should be compensated by the EPR system.

It should be noted that some industry representatives in the Reference Group consider a tax on chemical content in textile products to be prohibitively bureaucratic and costly to administer. 


\section{Policy package 2 - key findings}

\section{Voluntary collective EPR complemented by recycling certificates and raw material fees}

The package is based on the idea that instruments that increase the demand for recycled and reused textiles might increase the likelihood that a softer, voluntary approach to collection and sorting will prove to be effective.

Central to this policy package is a voluntary agreement between government and business, where willing businesses or branch associations sign a commitment to organising the collection of used textile and ensuring that they are subsequently used/recycled. This is strongly connected to the Nordic textile reuse and recycling commitment.
In addition to the points mentioned for the mandatory EPR system, critical factors of the voluntary EPR policy package include:

- Facilitating cooperation within the textile and clothing sector on the content of a voluntary collective $E P R$, including setting of targets

- Generating strong commitment and motivation from industry

- Expanding consumer awareness to act as a motivating driver for industry participation

A voluntary scheme runs the risk that only a few textile producers participate. EPR programmes with governmental involvement in tackling free riders tend to produce higher collection and recycling rates than strictly voluntary programmes. A voluntary EPR system wholly run by producers and brands might also prioritise recycling over reuse since recycling does not directly challenge the existing business model of high street retailers. To guard against this, the targets in the commitment at the core of the agreement need to strongly prioritise reuse. Introducing new collection systems in addition to existing ones also risks that good quality reusable textiles end up being recycled instead of being reused. Clear reuse targets and consumer guidance can minimise this risk, while collecting all textiles under one system for later sorting should maintain or even increase reuse.

Producers consulted on the draft policy packages have responded negatively to the prospect of a recycling certificate scheme. They argue that the scheme would be difficult to administer due to the many types of fibres and blends of fibres being used in textile products. 


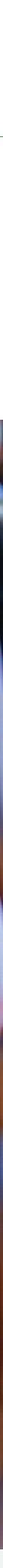




\section{Policy package 3 - key findings}

\section{Measures supporting new business models}

More than 20 different types of business models were mapped out. They all aim to extend the active lifetime of textile products through reuse or otherwise, and/or at the end of life.

In order to support and spread a broad range of these new business models, a pool of policy measures was created. The pool of policy measures tackles three key obstacles identified as being common to most new business models:

- Lack of quality and durability: in particular challenging models which aim to extend lifetimes such as leasing, second-hand businesses, resell of used own brand etc.
- Lack of awareness of alternative models: both among consumers but also amongst retailers and entrepreneurs

- Unfavourable price differential: between the high cost of labour in Nordic countries for carrying out repair, leasing and other services, and the cheap cost of imported textiles

The first and last challenges are intimately connected. The higher the quality and durability of average clothing, the more the repair and leasing options begin to look economic viable.

Suggested policy options comprise: - Financial assistance and demands for inclusion of sustainable design courses in design schools

- Labelling (Nordic Swan, Higg Index or otherwise) with durability information/criteria
- Minimum warranty periods for (certain types of) clothing/textiles

- Knowledge hub and advice bureau for start-up of new business models

- Nordic awards for new business models in textiles

- VAT reductions/removal for second-hand goods, repair services and leasing

- Government funding pool for startup investments in new business models within textiles

- Support given via competitive bidding for second hand shops/ departments in central shopping areas

- Unemployed wage subsidies earmarked for sustainable business models, plus tax benefits for social enterprises

- Resource tax on new textiles. 
A key factor for all of the alternative business models is the issue of quality. Reuse, second-hand, leasing and repair services are all dependent on a sufficient quality and durability of new textile products to allow a long active lifetime by many users. Moreover, the higher the quality of textiles, the higher the per article price. This makes repair, second-hand leasing etc. increasingly economically attractive to consumers in comparison to current "buy and dispose"-models.

In the long run, textile quality can be promoted via capacity building and education of designers and purchasers. In the short term it is important to provide incentives to produce textile products with a higher technical and aesthetic quality. A raw material fee can be a game-changer for the textile industry if set high enough, and strongly promote sales of fewer, high-quality items rather than large amounts of fast (low-quality) fashion.

None of the instruments on their own is likely to be able to bring about a paradigm shift in the way consumers access textile products. However, if all or many of the identified instruments are adopted in parallel, the potential for a paradigm shift is much stronger. Complementarity between the various instruments is strong: for example, durability labelling/testing and extended warranty periods are directly compatible. Knowledge hubs and various economic support measures can also be mutually beneficial.

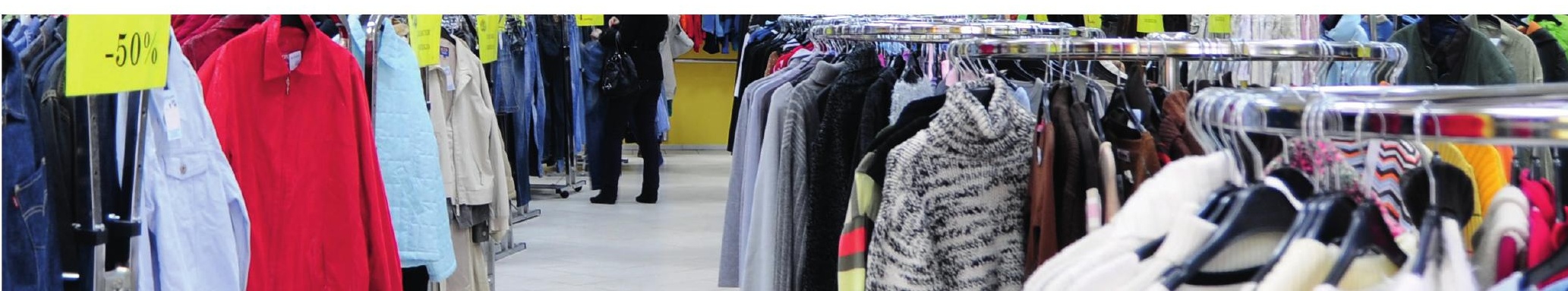




\section{General assessments}

Simple qualitative assessments of a number of models, including both the mandatory and the voluntary EPR models, were undertaken in order to formulate some general characteristics:

- When run collectively, mandatory EPR has the potential for capturing large quantities of used textiles cost effectively. Individual voluntary EPR schemes, however, include stronger incentives for so-called upstream effects i.e. improvements in design to benefit reuse or allow effective recycling. Collective EPR schemes can encourage these effects but only if designed carefully.

- Design for durability is an important supporting element of lease, repair, clothing libraries, luxury second hand and resell of own brand models. Policies are needed which encourage design for durability and higher quality.

- Traditional perceptions of selling, buying or owning textiles are a common barrier to all of the business models identified. Raising awareness of alternatives amongst consumers and producers alike is crucial to their dissemination and acceptance.

- The potential magnitude of collection is the most crucial characteristic with respect to overall environmental gains. Mandatory or widely adopted voluntary collective EPR systems can collect much larger volumes than in-store collection and resell of used own brand models.

- The reuse element gives by far the largest environmental gain per collected tonne compared to models based on recycling. A technological breakthrough in cost efficient high grade recycling combined with design of textiles for recycling would work in favour of all models.
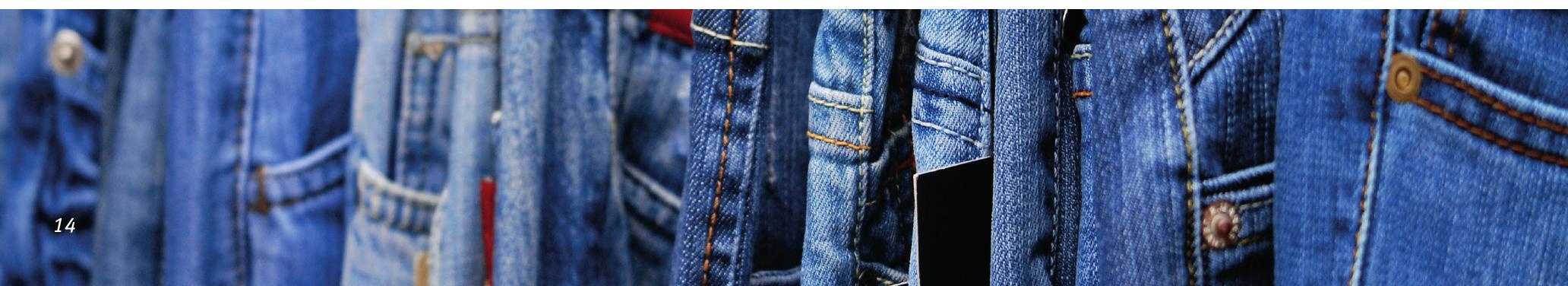


\section{Conclusions}

Mandatory and voluntary collective EPR systems would have a significant impact on collection of used textiles, but a more limited effect on the preconsumer (upstream) stages of the textile life cycle. On the other hand, widespread use of alternative business models, such as leasing and resell of own brand, have a clear upstream effect, but perhaps more minor impacts on overall collection, reuse and recycling.

The EPR systems have potential for creating green jobs in collection, reuse and recycling, but these jobs might, to a large extent, be created in regions where markets for sorting and low grade recycling already exists rather than in the Nordic countries. With limited development in sorting and recycling technology, the short-term effect will likely be export of mixed used textile fractions for sorting outside the Nordic countries. The alternative business models on the other hand are often more labour intensive and tend to create jobs involved in take-back, repair, laundering and re-sell of textiles. Such jobs need to be close to the consumer and thus would be placed in Nordic countries.

EPR systems, in particular a mandatory system, would create large flows of used textiles. This is a pre-requisite for investment in sorting and recycling technology. With proper supplementary measures, this can create an opportunity for increased investment in this area within and outside of the Nordic countries. This is not the case for most of the alternative business models, which primarily focus on prolonging the lifetime of textiles rather than recycling.
The many synergies between the different systems serve to strengthen and overcome individual systems' weaknesses. The voluntary or mandatory EPR systems are by definition mutually exclusive but either one of them can, and perhaps should, be accompanied by additional measures to promote alternative businesses such as leasing, clothing libraries, resell of own brand etc. Thus, the expanded collection of used textiles can be supplemented by upstream effects such as design for longer active lifetimes of products.

Supplementary policies - chemical taxes, recycling certificates and raw material fees - need to be further investigated in their application to textiles before implementation.

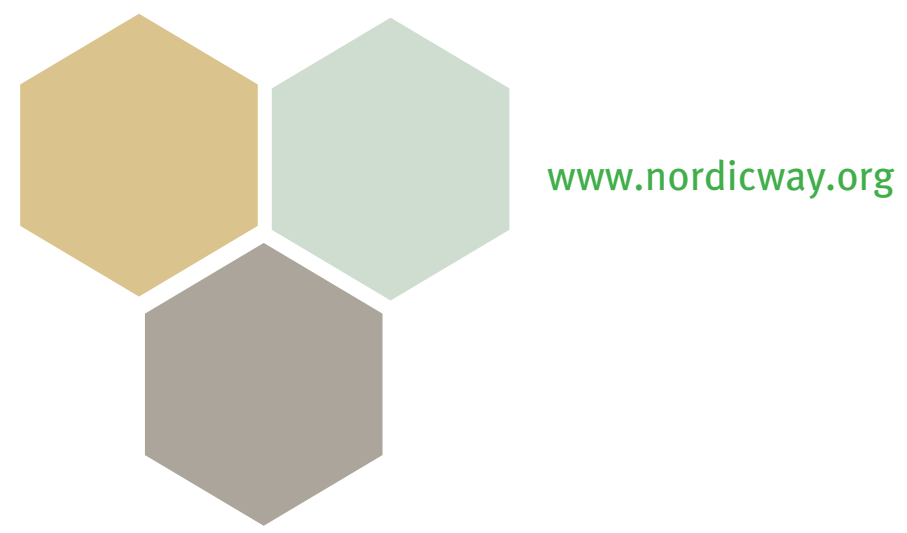




\section{norden}

Nordic Council of Ministers

\section{Ved Stranden 18}

DK-1061 København K

www.norden.org

This policy brief on Nordic textile reuse and recycling is part of the Nordic Prime Ministers' overall green growth initiative, The Nordic Region - leading in green growth. Read more in the web magazine Green Growth the Nordic Way at www.nordicway.org or at www.norden.org/greengrowth 